\title{
Chemoresistive Room-Temperature Sensing of Ammonia Using Zeolite Imidazole Framework and Reduced Graphene Oxide (ZIF-67/ rGO) Composite
}

\author{
Naini Garg, Mukesh Kumar, Neelam Kumari, Akash Deep,* and Amit L. Sharma*
}

Cite This: ACS Omega 2020, 5, 27492-27501

Read Online

ABSTRACT: The present work demonstrates the application of a composite of the zeolite imidazole framework (ZIF-67) and reduced graphene oxide (rGO), synthesized via a simple hydrothermal route for the sensitive sensing of ammonia. The successful synthesis of ZIF-67 and rGO composite was confirmed with structural and spectroscopic characterizations. A porous structure and a high surface area $\left(1080 \mathrm{~m}^{2} \mathrm{~g}^{-1}\right)$ of the composite indicate its suitability as a gas sensing material. The composite material was coated as a thin film onto interdigitated gold electrodes. The sensor displays a change in its chemoresistive property (i.e., resistance) in the presence of ammonia $\left(\mathrm{NH}_{3}\right)$ gas. A sensor response of $1.22 \pm 0.02$ [standard deviation (sd)] is measured for $20 \mathrm{ppm}$ of $\mathrm{NH}_{3}$, while it shows a value of $4.77 \pm$ 0.15 (sd) for $50 \mathrm{ppm}$ of $\mathrm{NH}_{3}$. The fabricated sensor is reproducible and offers a stable response, while also providing tolerance against humidity and some other volatile compounds. The average response and recovery times of the sensor, for $50 \mathrm{ppm} \mathrm{NH}_{3}$ concentration, are found to be $46.5 \pm 2.12$ (sd) and $66.5 \pm 2.12$ (sd) s, respectively. The limit of detection of the sensor was found to be $74 \mathrm{ppb}$.

\section{INTRODUCTION}

The detection of hazardous or toxic analytes, such as ammonia, methane, carbon monoxide, carbon dioxide, and so forth, is important in a wide range of applications such as food, health, safety, pharmacology, environmental monitoring, and so forth. Ammonia $\left(\mathrm{NH}_{3}\right)$ is a colorless and water-soluble gas used in a wide range of applications, such as agriculture, production of fertilizers, plastics, dyes, pharmaceuticals, chemical industries, refrigeration, and so forth. ${ }^{1}$ It is a flammable and corrosive gas with a pungent smell, with an odor threshold range of 5-50 ppm. ${ }^{2,3}$ A high concentration of $\mathrm{NH}_{3}$ is unpleasant and unhealthy for humans. The Occupational Safety and Health Administration (OSHA) has recommended the safety exposure limit of $8 \mathrm{~h}$ of $25 \mathrm{ppm}$ and short-term exposure limit of $15 \mathrm{~min}$ of $35 \mathrm{ppm}$ of $\mathrm{NH}_{3}$ gas in a workplace. ${ }^{2}$ The National Institute of Occupational Safety and Health (NIOSH), United States, recommends a safe limit of $\mathrm{NH}_{3}$ at workplaces as $25 \mathrm{ppm}$ for $10 \mathrm{~h}$ per day or $40 \mathrm{~h}$ per week. ${ }^{3}$ The exposure to extreme concentrations of $\mathrm{NH}_{3}$ might cause death, whereas low and continuous exposure could lead to various life-threatening diseases. ${ }^{2-4}$ As such, the human olfactory system is able to detect high $\mathrm{NH}_{3}$ concentrations by a pungent smell; however, it is challenging to detect low levels of ammonia at room temperature (RT). ${ }^{5}$

It is of great significance to develop highly sensitive and selective sensors that could detect $\mathrm{NH}_{3}$ at RT conditions. Various approaches using a variety of sensing materials have been employed to detect $\mathrm{NH}_{3} \cdot{ }^{4-12}$ The metal oxide-based gas sensors display good sensitivity, but these power-demanding devices are generally operated at high temperatures. ${ }^{13,14}$ The conducting polymers and their derivatives suffer from the swelling effect, long-term instability, and irreversibility problem under continuous exposure of $\mathrm{NH}_{3} .{ }^{15-17}$ The above limitations of the conventional materials necessitate further explorations of sensing materials that can work at RT.

Metal-organic frameworks (MOFs), also known as coordination compounds, are a relatively new class of porous materials receiving wide attention of the researchers. MOFs (1-, 2-, or 3-dimensional) are synthesized via the coordination bonding of metal ions with multidentate organic ligands. MOFs possess various unique features such as extremely high specific surface area, high structural/compositional flexibility, tunable pore size, adsorption-desorption capabilities, high crystallinity, and chemical and thermal stabilities. ${ }^{18-30}$ MOFs have been investigated as promising materials in various applications such as molecular sensing, ${ }^{18-20}$ gas storage, ${ }^{21}$ gas separation, ${ }^{22-24}$ catalysis, $^{25}$ drug delivery, ${ }^{26}$ organic lightemitting devices, ${ }^{27,28}$ gas probing, ${ }^{29}$ supercapacitors, and batteries. ${ }^{30-34}$ Zeolitic imidazole framework (ZIF) is a subclass

Received: August 18, 2020

Accepted: October 1, 2020

Published: October 13, 2020 
of MOFs possessing excellent thermal and chemical stabilities. $^{35}$ The ZIF MOFs are primarily composed of zinc or cobalt, linked to the deprotonated imidazole linkers through nitrogen atoms. Owing to a large surface area and accessible pores (close to $2 \mathrm{~nm}$ ), ZIFs have been explored in gas-sensing applications. Their hydrophobic nature has also been suggested to be useful in tolerating humid conditions. ${ }^{35,36}$ In recent years, ZIF-67 (cobalt-based MOF) has attracted attention as a material with excellent gas absorption properties. $^{36-42}$ To cite an example, $\mathrm{ZnO}$ nanorod-coated ZIF-67 has been proposed for the selective detection of formaldehyde. ${ }^{39}$ Interestingly, this study reported an unresponsive behavior of ZIF-67 toward $\mathrm{NH}_{3}$.

Because of the low concentration of freely availably charge carriers, most of the MOFs are characterized with a high energy band gap, and they behave similar to insulators. Hence, the development of MOF-based electrochemical sensors needs the creation of conduction pathways in the material. ${ }^{43,44}$ For this purpose, MOFs can be integrated with conducting polymers, carbon-nanomaterials, and metal nanoparticles. ${ }^{4-12}$ In this context, the composites of MOFs with reduced graphene oxide (rGO) show great promise. rGO possesses excellent conductivity, high surface-to-volume ratio, and functionalities. ${ }^{45-48}$ In addition, surface defects and oxygen functional groups in $\mathrm{rGO}$ can provide active sites for the adsorption of many target analytes, including gases. ${ }^{49,50}$

The application of plain rGO for the sensing of $\mathrm{NH}_{3}$ does not show promising results. ${ }^{51}$ In fact, rGO is better suited for $\mathrm{NH}_{3}$ sensing when it is used in a composite form, for example, with polymers like pyrrole, $p$-phenylenediamine, and polyaniline. ${ }^{52-56}$ In view of the limitations of individual ZIF-67 and rGO toward the detection of $\mathrm{NH}_{3}$ and also considering the advantages that their composite can offer, the present work explores the electrochemical potential of a ZIF-67/rGO composite for $\mathrm{NH}_{3}$ sensing. As the present study establishes, the ZIF-67/rGO composite is useful to detect $\mathrm{NH}_{3}$ at RT conditions with a detection limit satisfying the exposure guidelines of OSHA and NIOSH. To the best of authors' knowledge, this is the first report to describe the application of ZIF-67/rGO for $\mathrm{NH}_{3}$ sensing. As a significant highlight, the sensor is capable of detecting $\mathrm{NH}_{3}$ at $\mathrm{RT}$ conditions. Note that the previous studies have raised concerns on the applicability of the plain rGO-based $\mathrm{NH}_{3}$ sensors, as they might encounter interference from humidity. The ZIF-67/rGO composite behaves more as a hydrophobic material and tolerates the humid conditions to allow selective detection of $\mathrm{NH}_{3}$. The ZIF-67/rGO composite-based sensor has been evaluated for its sensitivity, selectivity, reproducibility, and stability.

\section{RESULTS AND DISCUSSION}

2.1. Structural Analysis. The X-ray diffraction (XRD) patterns of ZIF-67, rGO, and ZIF-67/rGO are shown in Figure 1 . In the case of ZIF-67, strong and sharp $2 \theta$ peaks are observed at $7,10,12,14,16$, and $18^{\circ}$ indexed to (011), (001), (112), (022), (013), and (222) crystal faces, respectively. The obtained peaks and their indexing are in good agreement with the earlier reports. ${ }^{57,58}$ A crystalline nature of ZIF-67 is also evident, and its crystallize size (as estimated from the Scherrer formula) is estimated to be around $550 \mathrm{~nm}$. In the case of the rGO sample, two main peaks at $24.7(002)$ and $43^{\circ}(101)$ are observed. $^{59}$ The composite sample, containing both ZIF-67 and rGO, displays almost all the ZIF-67-related characteristic peaks. Furthermore, it also shows a low-intensity peak at $25.2^{\circ}$,

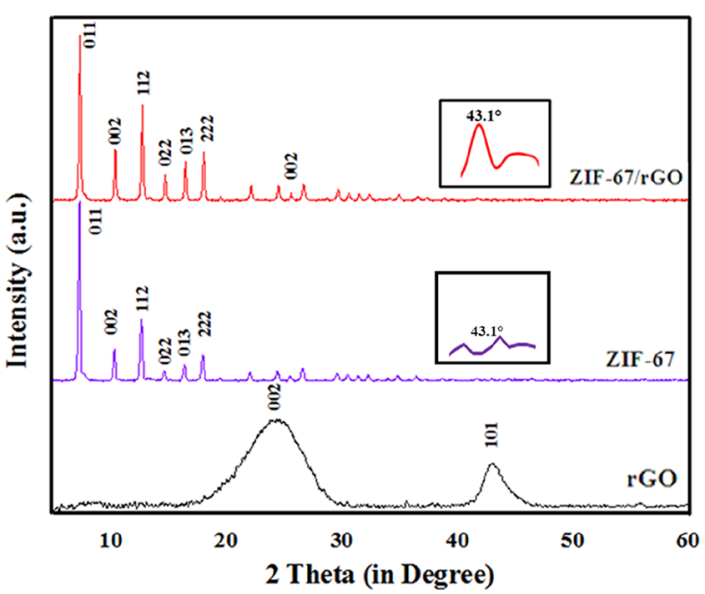

Figure 1. XRD patterns of rGO, ZIF-67, and ZIF-67/rGO. [Inset shows an enlarged view of the (101) peak of rGO in the composite].

indicating the presence of rGO as well. A slight shift in this rGO-related peak is realized, that is, from $24.7^{\circ}$ (rGO alone) to $25.2^{\circ}$ (ZIF-67/rGO). Moreover, another low intensity peak at $43.1^{\circ}$ (inset of Figure 1) also refers to successful formation of the desired ZIF-67/rGO composite. The low intensities of rGO-associated XRD peaks in the composite sample are due to the relatively weak diffractions compared to the more prominent ZIF-67-related peaks. ${ }^{30}$ The XRD investigations have verified a successful synthesis of the ZIF-67/rGO composite. The introduction of rGO in ZIF-67 does not influence the basic structural integrity of the MOF component.

2.2. Brunauer-Emmett-Teller Surface Area Analysis. $\mathrm{N}_{2}$ adsorption-desorption isotherm curves for rGO, ZIF-67, and ZIF-67/rGO samples are presented in Figure 2. Prior to

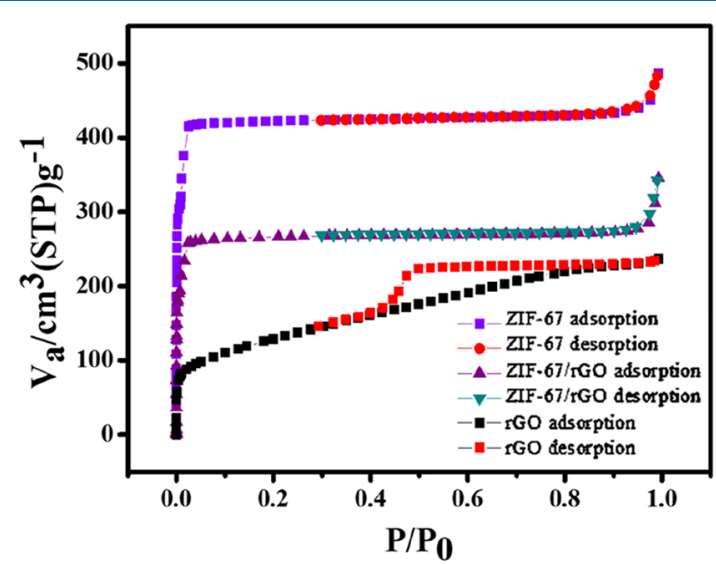

Figure 2. $\mathrm{N}_{2}$ adsorption-desorption isotherms for rGO, ZIF-67, and ZIF-67/rGO. $\left[P=\right.$ equilibrium pressure, $P_{0}=$ saturate pressure of adsorbate $\left(\mathrm{N}_{2}\right.$ gas $), V_{\mathrm{a}}=$ volume of gas adsorbed].

de-gassing, the samples were placed in a vacuum oven at $70{ }^{\circ} \mathrm{C}$ for $24 \mathrm{~h}$ to ensure the removal of guest molecules. As the results show, an increase in the relative pressure $\left(P / P_{0}\right)$ leads to the increasing sorption of $\mathrm{N}_{2}$ gas. Initially, $\mathrm{N}_{2}$ molecules access the material to form a monolayer. The increasing partial pressure results in the subsequent formation of the multilayer until there is a complete coverage in the bulk material to fill all the pores. This process is modeled mathematically to derive important material characteristics, such as pore volume, pore diameter, and surface area. Brunauer-Emmett-Teller (BET) 
specific surface area values for ZIF-67 and rGO samples are found to be 1995 and $459 \mathrm{~m}^{2} \mathrm{~g}^{-1}$, respectively. The observed BET surface area value $\left(1995 \mathrm{~m}^{2} \mathrm{~g}^{-1}\right)$ of ZIF-67 is higher than previously reported values for the same MOF (Table 1). A

Table 1. Comparison of Specific Surface Area Values between the Synthesized and Previously Reported ZIF-67

\begin{tabular}{ccccc} 
s. no. & $\begin{array}{c}S_{\mathrm{BET}} \\
\left(\mathrm{m}^{2} / \mathrm{g}\right)\end{array}$ & $\begin{array}{c}\text { pore volume } \\
\left(\mathrm{cm}^{3} / \mathrm{g}\right)\end{array}$ & $\begin{array}{c}\text { pore size } \\
(\mathrm{nm})\end{array}$ & refs \\
1 & 1392.30 & 0.7324 & 1.01 & 63 \\
2 & 1717.00 & & & 31 \\
3 & 621 & & & 30 \\
4 & 798 & 0.6088 & & 34 \\
5 & 1832.2 & & 1.26 & 40 \\
6 & 947 & & 2.106 & 32 \\
7 & 1004 & 0.39 & & 41 \\
8 & 1094.3 & 0.576 & & 58 \\
9 & 1833 & & & 64 \\
10 & 1245 & 0.665 & & 65 \\
11 & 1325 & & $\mathbf{1 . 5}$ & present work \\
12 & 316 & 0.17 & & \\
13 & 1995 & $\mathbf{0 . 7 4}$ & & \\
\hline
\end{tabular}

larger surface area value of the herein synthesized ZIF-67 may be due to the optimized synthesis process and the degassing of the samples during pretreatment step, which guaranteed removal of pre-adsorbed species. ${ }^{61,62}$ The presence of a high surface area ZIF-67 component in the composite is likely to allow the adsorption of a more number of gas molecules, hence resulting in an increased sensitivity. BET characteristics of the rGO sample are an indicator of its significantly exfoliated form. ${ }^{60}$

BET surface area analysis of ZIF-67/rGO has yielded the values of surface area $=1080 \mathrm{~m}^{2} \mathrm{~g}^{-1}$, mean pore volume $=0.51$ $\mathrm{cm}^{3} \mathrm{~g}^{-1}$, and mean pore diameter $=1.8 \mathrm{~nm}$. The above surface area value of the ZIF-67/rGO composite is better compared to that reported by a previous study with the same material. ${ }^{32}$ In comparison to ZIF-67 alone, the ZIF-67/rGO composite shows lower values of specific surface area and pore volume. The wrapping of rGO over ZIF-67 crystals and a partial approach of smaller particles within the MOF pores should be reasoned for the above observation. In parallel, the ZIF-67/ rGO composite has a slightly increased average pore diameter, which is explained by the structural strains induced in the ZIF67 framework after the addition of rGO. ${ }^{60}$

2.3. Spectroscopic and Morphological Measurements. The recorded IR spectra for the different synthesized materials are shown in Figure 3a. In the case of ZIF-67, sharp bands are observed at 3440, 3130, 2927, 1580, 1418, 1300, $1170,1140,991,753,684$, and $426 \mathrm{~cm}^{-1}$. A wide band at 3440 $\mathrm{cm}^{-1}$ can be attributed to $\mathrm{O}-\mathrm{H}$ stretching vibrations of $\mathrm{H}_{2} \mathrm{O}$. The bands at 3130 and $2927 \mathrm{~cm}^{-1}$ can be ascribed to $\mathrm{C}-\mathrm{H}$ stretching from the aliphatic methyl group and the aromatic ring present in the linker, respectively. ${ }^{65} \mathrm{~A}$ band at $1580 \mathrm{~cm}^{-1}$ can be associated with stretching mode of $\mathrm{C}=\mathrm{N} .{ }^{32}$ The bands around $1500-900 \mathrm{~cm}^{-1}$ can be attributed to the ring stretching and bending of the linker molecule. ${ }^{58}$ A sharp band at 426 $\mathrm{cm}^{-1}$ reflects $\mathrm{Co}-\mathrm{N}$ stretching mode, which verifies the bonding of Co with $\mathrm{N}$ of the 2-methyl imidazole linker. ${ }^{66}$ Fourier transform infrared (FT-IR) studies have confirmed a successful synthesis of ZIF-67. The ZIF-67/rGO sample contains all the important bands to suggest that the vital material characteristics are preserved even after the composite formation reaction.

The UV-vis absorption profiles of ZIF-67 and ZIF-67/rGO are presented in Figure $3 \mathrm{~b}$. The shoulder doublet peaks at 539 and $596 \mathrm{~nm}$ are associated with the characteristic transitions of tetrahedral $\mathrm{Co}^{2+}$. UV-vis light absorption characteristics of the composite are also almost identical to suggest that the basic molecular structure of ZIF-67 does not change even in the presence of $\mathrm{rGO}^{63,65}$

Scanning electron microscopy (SEM) and high resolution transmission electron microscopy (TEM) micrographs of ZIF67 and ZIF-67/rGO samples are presented in Figure $4 a-c$ and $\mathrm{d}-\mathrm{f}$, respectively. The polyhedral structure of ZIF-67 (Figure $4 \mathrm{a}$ ) is in good agreement with earlier reports. ${ }^{57,58}$ The average size of a ZIF-67 crystal is $530 \pm 50 \mathrm{~nm}$ (based on estimation with 23 number of particles), which is close to the XRD-based approximation. SEM images of the ZIF-67/rGO composite sample (Figure 4b) indicate the presence of ZIF-67 crystals over the rGO sheet. The results shown in Figure 4c suggest that rGO does not necessarily cover the whole ZIF-67 structure. As a result, the pores of the MOF remain accessible. HR-TEM analysis (Figure 4e,f) provides another evidence about the assembly of ZIF-67 over graphene sheets; further, HR-TEM images also clearly show that ZIF-67 crystals are connected in the composite structure via linkage through rGO nanosheets.

The elemental composition of ZIF-67/rGO, as analyzed by the energy-dispersive X-ray (EDX) technique, is presented in Figure 5a. The study confirms the presence of Co along with $\mathrm{C}, \mathrm{O}$, and $\mathrm{N}$.

2.4. Contact Angle Measurements. The contact angle studies were performed using the sessile drop method (Figure $5 b)$. For this, slurry of composite powder was prepared and deposited over a glass substrate before drying at $70{ }^{\circ} \mathrm{C}$ under
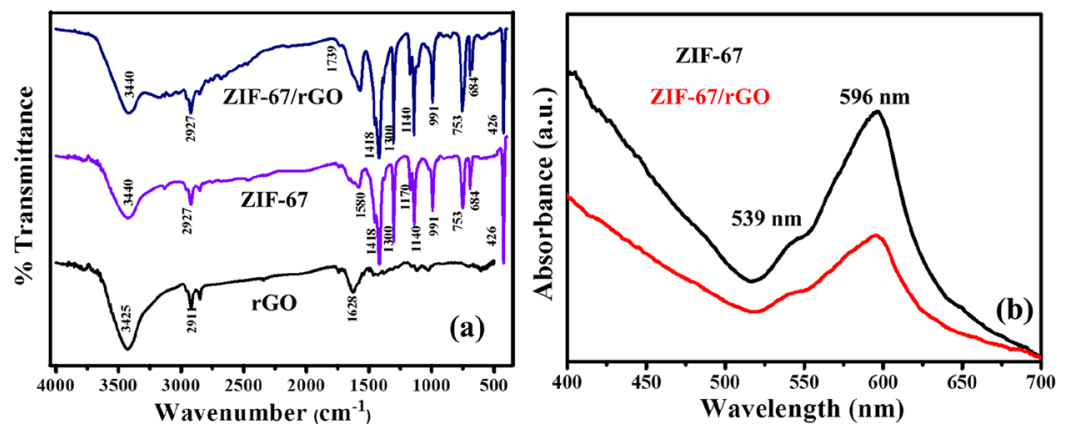

Figure 3. (a) FT-IR spectra of rGO, ZIF-67, and ZIF-67/rGO; (b) UV-visible (UV-vis) light absorption spectra of ZIF-67 and ZIF-67/rGO. 



Figure 4. $(\mathrm{a}-\mathrm{c})$ Field-emission SEM micrographs and $(\mathrm{d}-\mathrm{f})$ high-resolution TEM images of ZIF-67 and ZIF-67/rGO composite.

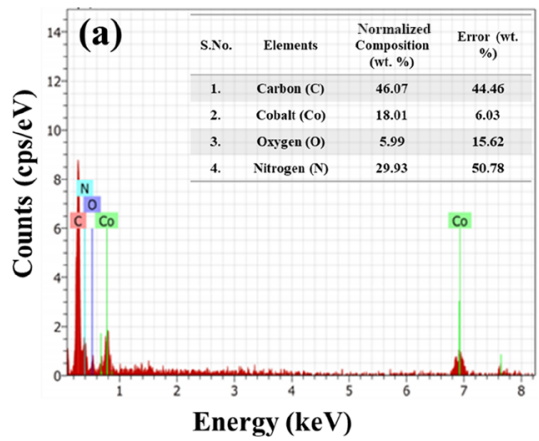

(b)

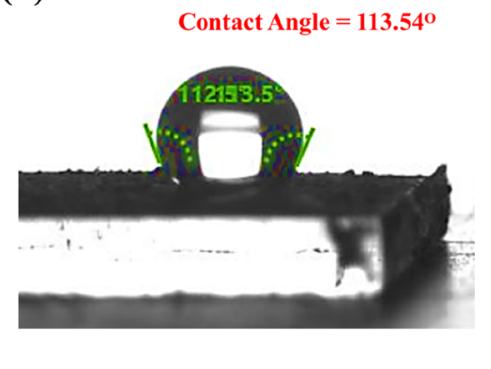

Figure 5. (a) EDX and (b) contact angle measurement of the ZIF-67/rGO composite.
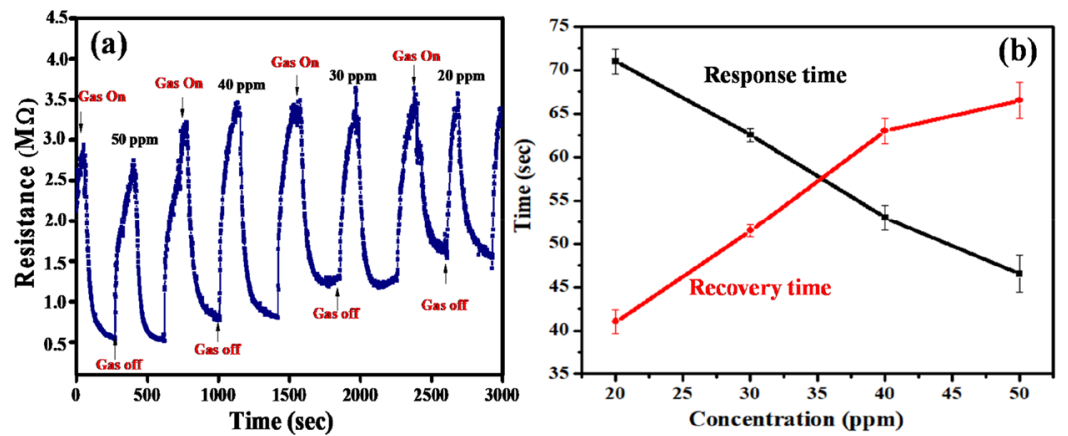

Figure 6. (a) Response of a sensor against different $\mathrm{NH}_{3}$ concentrations varying from 20 to $50 \mathrm{ppm}$ at $\mathrm{RT}$; (b) response and recovery time as a function of varying $\mathrm{NH}_{3}$ concentrations (term "gas on" indicates that the valve is opened to allow the diffusion of gas inside the chamber; term "gas off" indicates the opening the lid of the chamber and flushing with fresh air so as to evacuate the residual gas).

vacuum. In general, a surface is considered hydrophobic if the water contact angle is greater than $90^{\circ}$. ZIF-67 is characterized with a contact angle of $108.58^{\circ} \pm\left(0.43^{\circ}\right)$ (Figure S1), indicating its hydrophobic nature. ${ }^{67,68}$ The ZIF-67/rGO composite displays a contact angle of $113.54^{\circ} \pm\left(0.48^{\circ}\right)$. As such, the hydrophobic nature of the ZIF-67/rGO composite should help in minimizing the interference from water vapors (humidity) during sensor applications. ${ }^{69}$

2.5. Ammonia Sensing Studies. The resistance of the ZIF-67/rGO film electrode has been monitored as a function of different $\mathrm{NH}_{3}$ concentrations. The response $(R)$ of the sensor has been calculated using the following expression

$$
R=\left(R_{\mathrm{a}}-R_{\mathrm{g}}\right) / R_{\mathrm{g}}
$$

where $R_{\mathrm{a}}$ and $R_{\mathrm{g}}$ are the resistance values measured in the presence of pure air and against ammonia, respectively.
Figure S2a-d shows the sensor response at different $\mathrm{NH}_{3}$ concentrations $(20-50 \mathrm{ppm})$. Figure $6 \mathrm{a}$ summarizes the collective response of the sensor. All the measurements were carried out under RT conditions. Response time is referred as the time taken for the sensor response to reach to $90 \%$ of the sensor's baseline value. Likewise, the recovery period is the time taken by the sensor to revert to $10 \%$ from its baseline resistance value. A decrease in the sensor's resistance is observed in the presence of $\mathrm{NH}_{3}$. For $50 \mathrm{ppm}$ concentration, the sensor resistance decreases from 3.0 to $0.75 \mathrm{M} \Omega$ in $45 \mathrm{~s}$ and saturates to around $0.52 \pm 0.01 \mathrm{M} \Omega$. During recovery, that is, the evacuation of residual gas from the chamber by opening the lid and flushing the sensing film with fresh air, the resistance reverts to its baseline value in about $68 \mathrm{~s}$. For 50 ppm $\mathrm{NH}_{3}$, the response of the sensor (eq 1 ) is calculated to be $4.77 \pm 0.15$. Other tested concentrations also caused the sensor to respond in a manner similar to that explained above. Higher $\mathrm{NH}_{3}$ concentrations are detected with proportionally 
Table 2. Important Performance Parameters of the ZIF-67/rGO Sensor toward Different $\mathrm{NH}_{3}$ Concentrations

$\begin{array}{ccccc}\text { s. no. } & \text { concn }(\mathrm{ppm}) & \text { response }\left[\left(R_{\mathrm{a}}-R_{\mathrm{g}}\right) / R_{\mathrm{g}}\right] & \text { av response time }(\mathrm{s}) & \text { av recovery time }(\mathrm{s}) \\ 1 & 20 & 1.22 \pm 0.02 & 71 \pm 1.41 & 41 \pm 1.41 \\ 2 & 30 & 1.89 \pm 0.02 & 62.5 \pm 0.70 & 51.5 \pm 0.71 \\ 3 & 40 & 2.79 \pm 0.06 & 53 \pm 1.41 & 63 \pm 1.41 \\ 4 & 50 & 4.77 \pm 0.15 & 46.5 \pm 2.12 & 0.90 \pm 0.03 \\ \end{array}$
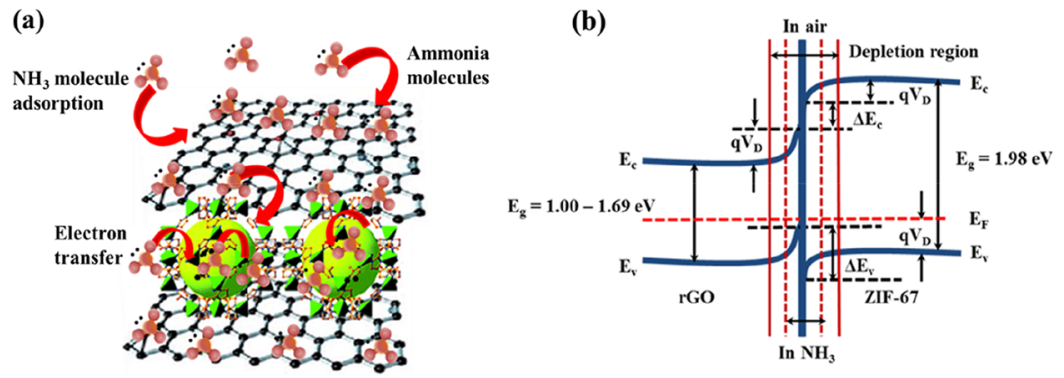

Figure 7. Schematic of mechanism of $\mathrm{NH}_{3}$ sensing with the ZIF-67/rGO electrode. (a) Absorption of gas molecules by ZIF-67 and charge transfer across the rGO sheets and (b) energy band diagram.

larger values of $R$ (Figure $8 \mathrm{a}$ and Table 2). Further, the response and recovery times at different $\mathrm{NH}_{3}$ concentrations are depicted in Figure 6b. Larger $\mathrm{NH}_{3}$ concentrations are detected with relatively less response times, but increased recovery times.

The limit of detection (LOD) of the sensor has been calculated using eq 2 . $^{70}$

$$
\mathrm{LOD}=Y_{\mathrm{b}}+3 S_{\mathrm{b}}=Y_{\mathrm{b}}+3 \times \sqrt{\frac{\sum_{i=1}^{n}\left(y_{i}-y_{i}^{\prime}\right)^{2}}{n-2}}
$$

where $Y_{\mathrm{b}}=$ intercept of the calibration curve and $S_{\mathrm{b}}=$ standard deviation of blank measurements; $y_{i}$ and $y_{i}^{\prime}$ are the experimental and the theoretical values (from the calibration curve), respectively, obtained for all of the concentrations tested; $n=$ number of samples tested. The LOD has been estimated to be $0.074 \mathrm{ppm}$ (74 ppb). The measurement error in the detection limit of the ZIF-67/rGO sensor is calculated to be \pm 0.015 .

2.6. Gas Sensing Mechanism. The formation of the ZIF$67 / \mathrm{rGO}$ composite is primarily governed via $\pi-\pi$ stacking between ZIF-67 and rGO. The interconnection of ZIF-67 with rGO nanosheets provides electronic pathways for the charge transfer across the material. A porous nature and a large surface area of ZIF-67 provide enhanced density of the active surface sites to allow the adsorption of $\mathrm{NH}_{3}$ molecules. The ZIF-67/ rGO film experiences a decrease in its resistance property when exposed to $\mathrm{NH}_{3}$ molecules. This trend is in contrast to some earlier reported rGO-based $\mathrm{NH}_{3}$ sensors, wherein the material resistance increased upon exposure to $\mathrm{NH}_{3} \cdot{ }^{52}$ In the case of $\mathrm{rGO}$, the increase in the film resistance can be explained by the hole depletion phenomenon. Under the ambient environmental conditions, rGO exhibits a p-type semiconducting behavior owing to the oxygen moieties and holes as the major carrier concentrations. $\mathrm{NH}_{3}$ bears an electron-donating nature, and therefore, its adsorption over rGO sheets results in a decrease in the concentration of the holes. Consequently, rGO-based sensors would show an increased resistance in the presence of $\mathrm{NH}_{3}$. A contrasting property of the ZIF-67/rGO composite can be explained on the basis of its n-type semiconducting behavior (Figure 7a). In n-type semiconductors, the electrons are the dominant charge carriers. In air, the material layer adsorbs oxygen molecules (eq 3). The charge carriers (i.e., electrons) then cause the formation of charged oxygen species (eq 4 ).

$$
\begin{aligned}
& \mathrm{O}_{2}(\text { gas }) \rightarrow \mathrm{O}_{2} \text { (adsorbed) } \\
& \mathrm{O}_{2}(\text { adsorbed })+\mathrm{e}^{-} \rightarrow \mathrm{O}_{2}^{-} \\
& 4 \mathrm{NH}_{3}(\text { adsorbed })+5 \mathrm{O}_{2}^{-} \rightarrow 4 \mathrm{NO}+6 \mathrm{H}_{2} \mathrm{O}+5 \mathrm{e}^{-}
\end{aligned}
$$

A depletion in concentration of electrons results in a decreased conductivity or an increased resistance. The exposure of ZIF-67/rGO films to $\mathrm{NH}_{3}$ (reducing gas) leads to an interaction between the unsaturated metal sites present in the porous MOF structure and the lone pair of electrons of $\mathrm{NH}_{3}{ }^{71}$ The absorbed gas then interacts with oxygen species and releases nitric oxide (NO) and water (eq 5). The captured electrons are released back in the conduction band. As the charge carrier concentration (number of electrons) is increased in the sensing layer (n-type characteristic), a proportional decrease in the resistance is observed. During the above process, rGO plays its role of a charge transfer layer. Because ZIF-67 provides a large number of absorption sites, the present sensor has yielded significant detection sensitivity.

Figure $7 \mathrm{~b}$ shows the energy band diagram of ZIF-67/rGO. Note that ZIF-67 and rGO have different Fermi levels. In a heterojunction of ZIF-67 and rGO, the charge transfer takes place from the material with higher $($ ZIF-67 $=1.98 \mathrm{eV})$ to lower work function $(\mathrm{rGO}=1.00-1.69 \mathrm{eV})$ till Fermi levels are matched. ${ }^{72}$ The width of the depletion layer reduces as the electron-donating $\mathrm{NH}_{3}$ molecules are absorbed and interact with ZIF-67/rGO layer. It subsequently results in a decrease in the film resistance.

2.7. Effect of Humidity. Humidity can influence the performance of an ammonia sensor during practical applications, particularly when operated under RT conditions. ${ }^{55}$ Hence, the performance of the ZIF-67/rGO sensor has been evaluated in the presence of two different relative humidity $(\mathrm{RH})$ conditions. For these investigations, identical conditions as kept during the analysis of 20 and $50 \mathrm{ppm} \mathrm{NH}_{3}$ were maintained. Selected aliquots (i.e., 300 and $750 \mu \mathrm{L}$ ) of water were evaporated inside the chamber. The resistance of the sensor, once stabilized, was monitored for the next $1000 \mathrm{~s}$. 

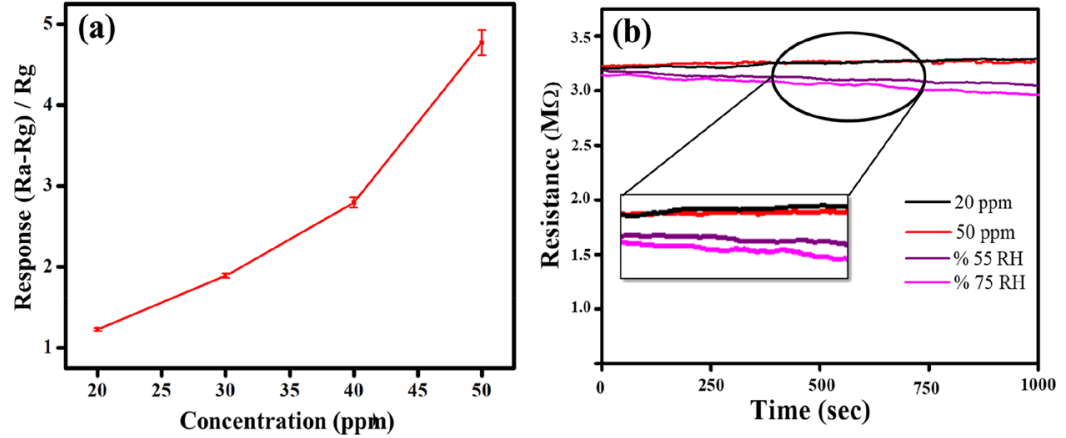

Figure 8. Comparative response of the ZIF-67/rGO sensor for $\mathrm{NH}_{3}$ and $\mathrm{RH}$. (a) Response with different concentrations of $\mathrm{NH}_{3}$; (b) response of the sensor against humid conditions [(i) 300 and $750 \mu \mathrm{L}$ water, which are equivalent to the volume of $\mathrm{NH}_{3}$ solution introduced in the chamber to produce 20 and $50 \mathrm{ppm} \mathrm{NH}_{3}$ vapors, respectively; (ii) 55 and 75\% $\mathrm{RH}$ inside the sensing chamber]. Inset in (b) shows the enlarged portion of the curve marked with a circle. Note that all the experiments were conducted at RT.

As the results depict (Figure $8 \mathrm{~b}$ ), the sensor maintains a steady response. The ZIF-67/rGO thin film tolerates humidity partially because of its hydrophobic nature. The study was further extended to investigate the effect of elevated $\mathrm{RH}$, that is, 55 and $75 \%$ (Figure $8 \mathrm{~b}$ ). These conditions cause a limited drop in the sensor resistance. As expected, the reduction is slightly more pronounced for $75 \% \mathrm{RH}$ as compared to $55 \%$ $\mathrm{RH}$. This slight lowering in the resistance can be explained by the fact that the water molecules get adsorbed in rGO interlayers via weak hydrogen bonds with the epoxy oxygen atoms. As a result, the material experiences slightly enhanced proton conductivity governed by the proton hopping mechanism. ${ }^{73}$ Notably, the response of ZIF-67/rGO toward humidity is still significantly less when compared to $\mathrm{NH}_{3}$.

2.8. Selectivity Studies. The sensor's selectivity toward $\mathrm{NH}_{3}(100 \mathrm{ppm})$ in the presence of other vapors, for example, methanol, ethanol, acetone, and 2-propanol (100 ppm each) has been examined. The responses $(R)$ were calculated and have been summarized in Figure S3. As these results indicate, the ZIF-67/rGO sensor is fairly selective to $\mathrm{NH}_{3}$. Its response to $\mathrm{NH}_{3}$ is significantly large compared to other tested volatiles. The presence of the lone electron pair in $\mathrm{NH}_{3}$ can be taken as the reason for the observed selectivity. Other tested vapor molecules do not influence the charge transfer mechanism within the ZIF-67/rGO framework.

2.9. Sensor Stability and Reproducibility. The stability and reproducibility of the ZIF-67/rGO sensor have been investigated. The reproducibility of the fabricated sensor was checked by exposing the sensor to $30 \mathrm{ppm} \mathrm{NH}_{3}$ for 3 consecutive days, maintaining identical environmental conditions. As the results presented in Figure S4a suggest, the ZIF$67 /$ rGO sensor provides fairly reproducible results. In order to check the stability of the sensor, its response was checked after 20 days of storage. We observed almost unchanged sensor response. The deviation in the response and recovery times is limited to less than $5 \%$ to suggest a long-term stability of the sensor (Figure S4b).

A comparison of the performance of the ZIF-67/rGO sensor for $\mathrm{NH}_{3}$ with some previously reported rGO- or MOF-based similar systems is summarized in Table S1. This comparison, made on the basis of some critical parameters like sensitivity, response, and recovery time, highlights that the ZIF-67/rGO composite is a useful sensory material to develop an efficient $\mathrm{NH}_{3}$ detector.

\section{CONCLUSIONS}

A composite of ZIF-67 and rGO (ZIF-67/rGO) has been synthesized using a hydrothermal route. The successful synthesis of this composite has been confirmed with various analytical techniques. The surface morphology shows the accumulation of ZIF-67 crystals over rGO sheets. ZIF-67/rGO has been obtained as a material with a high surface-to-volume ratio $\left(1080 \mathrm{~m}^{2} \mathrm{~g}^{-1}\right)$, which is an evidence of its potential usefulness in gas-sensing applications. Thin films of ZIF-67/ rGO have been deposited over the interdigitated gold electrodes (IDEs) to construct a thin film sensor. This sensor has been successfully demonstrated for the RT-based detection of $\mathrm{NH}_{3}(20-50 \mathrm{ppm})$. The sensor has displayed a fairly high response, that is, $1.22 \pm 0.02$ and $4.77 \pm 0.15$ for 20 and 50 ppm $\mathrm{NH}_{3}$, respectively. These tremendous sensing characteristics of the fabricated sensor are attributed to the high surfaceto-volume ratio of the composite, which provides more adsorption-desorption sites. The ZIF-67/rGO sensor has allowed the sensitive and fairly selective detection of $\mathrm{NH}_{3}$. The sensor is also reproducible and environmentally stable.

Limitation of the ZIF-67/rGO sensor is its slightly large response and recovery times. Because the main idea of the present investigation was to develop an RT-based sensing method, the material needs more time for regeneration. In future, the effect of film thickness and operating temperature can be investigated to further improve the performance of the sensor.

\section{EXPERIMENTAL SECTION}

4.1. Materials and Characterization. All the chemicals, including cobalt nitrate hexahydrate $\left[\mathrm{Co}\left(\mathrm{NO}_{3}\right)_{2} \cdot 6 \mathrm{H}_{2} \mathrm{O}\right]$, 2methyl imidazole $\left[\mathrm{C}_{4} \mathrm{H}_{6} \mathrm{~N}_{2}\right]$, and graphite flakes, were purchased from Sigma-Aldrich. Ammonia solution (25\%) and some other solvents (ethanol, methanol, acetone, and 2propanol) were purchased from Merck. All the chemicals were used as received without further purification, unless otherwise specified. Distilled water $(18.2 \mathrm{M} \Omega \mathrm{cm})$ was obtained from the Evoqua water purification system (Evoqua LaboStar Pro TWF UV, USA). The IDEs were purchased from DropSens, Spain.

XRD studies were carried out using an X-ray diffractometer (D8 Advance, Bruker, Germany; $\mathrm{Cu} \mathrm{K} \alpha \lambda=1.5418 \AA ̊ \AA 0$; $40 \mathrm{kV}$ and $40 \mathrm{~mA} ; 2 \theta$ range $=5-60^{\circ}$; scan rate $=1^{\circ} \mathrm{min}^{-1}$; scan size $\left.=0.02^{\circ}\right)$. The specific surface area $\left(S_{\mathrm{BET}}\right)$ and the pore diameters (at a relative pressure of $P / P_{0}=0.990$ ) of the samples were calculated from nitrogen physisorption experi- 


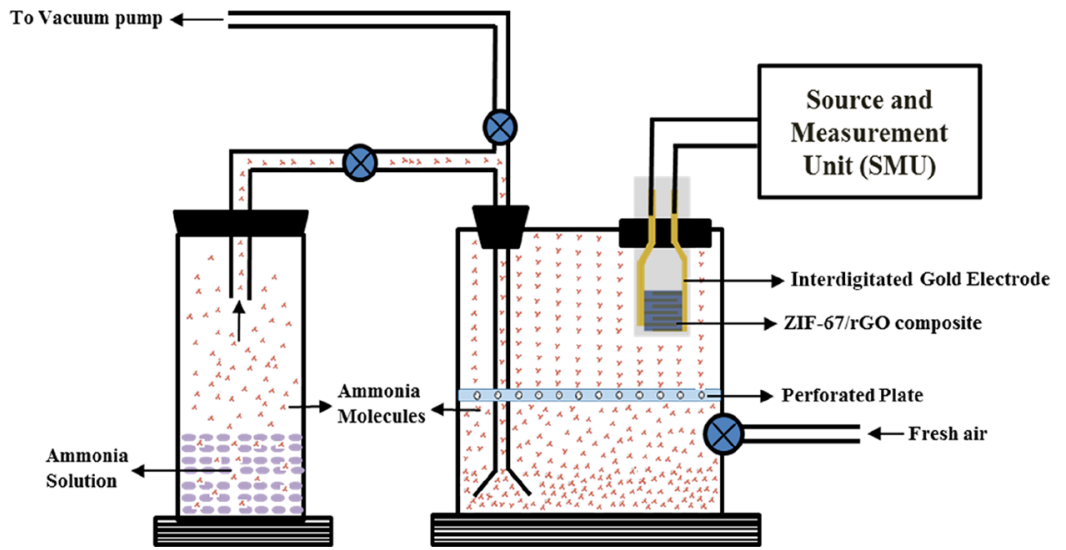

Figure 9. Schematic of the ammonia sensing setup.

ments $(77 \mathrm{~K})$ performed on a BET surface area analyzer (BELSORP Max sorptometer, Microtrac, Japan). The spectroscopic studies were carried out using FT-IR (Spectrum II, PerkinElmer, USA, wavenumber range $=4000-400 \mathrm{~cm}^{-1}$, spectral resolution $=4 \mathrm{~cm}^{-1}$ ) and UV-vis (Cary 5000, Agilent, USA, step size $=0.1 \mathrm{~nm}$ ) spectrophotometers. The morphological analyses were performed with a high-resolution transmission electron microscope (JEOL 2100 Plus, Japan, using a copper grid of 200 mesh) and a field-emission scanning electron microscope (SU8010FEG, Hitachi, Japan) equipped with EDX. For field-emission SEM, the samples were sputtercoated with platinum before placing them to the holder stage. The contact angle of the films was measured using a drop shape analyzer (Kruss, DSA 100E, Germany) at RT $(25 \pm 2$ ${ }^{\circ} \mathrm{C}$ ). The current-voltage measurements were performed with a source and measurement unit (B2901A, Agilent, USA). The RH was calibrated by a thermohygrometer (HTC 288ATH; temperature range: -50 to $70{ }^{\circ} \mathrm{C}$; humidity range: $10-90 \%$ $\mathrm{RH}$; resolution: $1 \% \mathrm{RH}$ ).

4.2. Synthesis of GO and rGO. First, graphene oxide (GO) was synthesized according to the modified Hummer's method. ${ }^{74}$ It was further reduced using ascorbic acid $(500 \mathrm{mg}$ in $100 \mathrm{~mL}$ water) as the reducing agent. ${ }^{32}$ Briefly, GO $(1 \mathrm{mg} /$ $\mathrm{mL}$ ) was dispersed in ascorbic acid solution by stirring for $1 \mathrm{~h}$ at $95{ }^{\circ} \mathrm{C}$. The reaction contents were allowed to stand for $12 \mathrm{~h}$ at RT. The rGO was then washed several times with water and finally dried at $60{ }^{\circ} \mathrm{C}$.

4.3. Synthesis of ZIF-67 and ZIF-67/rGO. ZIF-67 was synthesized according to an earlier reported hydrothermal route. ${ }^{34}$ Cobalt nitrate hexahydrate $\left[\mathrm{Co}\left(\mathrm{NO}_{3}\right)_{2} \cdot 6 \mathrm{H}_{2} \mathrm{O}\right](450$ $\mathrm{mg}, 2 \mathrm{mM})$ and 2-methylimidazole $\left[\mathrm{C}_{4} \mathrm{H}_{6} \mathrm{~N}_{2}\right](5.5 \mathrm{~g}, 67 \mathrm{mM})$ solutions were prepared in 3 and $20 \mathrm{~mL}$ of distilled water, respectively (sonication for $1 \mathrm{~h}$ ). These were mixed and stirred for $6 \mathrm{~h}$ (at RT) to allow the formation of a purple-colored precipitate, which was collected through centrifugation (8000 rpm for $15 \mathrm{~min}$ ). The material was washed with water and ethanol till the filtrates became clear. The final product was dried at $80{ }^{\circ} \mathrm{C}$ for $24 \mathrm{~h}$ in a vacuum oven.

The ZIF-67/rGO composite was also prepared as per the above procedure, but in the pre-presence of $\mathrm{rGO}$ powder (45 $\mathrm{mg}$ ). It may be noted that the precipitate obtained in this case had a royal-bluish appearance. All the remaining steps were similar as explained in the preceding para for the synthesis of ZIF-67. The formation of the composite material can be explained considering the possible interactions between the reactants. The co-presence of $\mathrm{Co}\left(\mathrm{NO}_{3}\right)_{2} \cdot 6 \mathrm{H}_{2} \mathrm{O}$ and rGO suspension resulted in weak interaction between $\mathrm{Co}^{2+}$ ions and oxygen-containing functional groups on the surface of rGO. Further, the addition of 2-methylimidazole (linker) into the above mixture caused the coordination of the linker with $\mathrm{Co}^{2+}$. The rGO sheets stacked in between the formed MOF crystals.

4.4. Sensor Fabrication and Analyte Response Measurement. Viscous slurry of the composite was prepared in $N$-methyl-2-pyrrolidone $(9: 1, \mathrm{w} / \mathrm{w})$. A suitable amount of the slurry was then drop-cast onto the defined working area (6 $\mathrm{mm} \times 6 \mathrm{~mm})$ of the IDEs. The prepared electrodes were then dried at $80^{\circ} \mathrm{C}$ for overnight to ensure a proper adhesion of the coating material onto the electrode surface.

An in-house designed chamber of $20 \mathrm{~L}$ capacity was used for the sensing experiments (Figure 9). The fabricated sensor, placed inside the chamber at a fixed position, was connected to a current-voltage source. A specifically designed connector was used to draw a stable response from the IDEs. Initially, the baseline resistance was recorded in the presence of air. After recording the response for different $\mathrm{NH}_{3}$ concentrations, the chamber was evacuated by opening the lid of the chamber manually. A vacuum pump was used to further evacuate the chamber fully so as to remove any residual gas molecules before the subsequent experiments. The $\mathrm{NH}_{3}$ concentration (in $\mathrm{ppm}$ ) in the chamber was calculated using eq $6 .^{75}$

$$
C(\mathrm{ppm})=\frac{V_{\mathrm{A}} \times D_{\mathrm{A}} \times T \times 8.2 \times 10^{4}}{M_{\mathrm{A}} \times V_{\mathrm{C}}}
$$

where $V_{\mathrm{A}}=$ volume of the liquid $\mathrm{NH}_{3}(\mathrm{~mL}), D_{\mathrm{A}}=$ density of liquid $\mathrm{NH}_{3}(\mathrm{~g} / \mathrm{mL}), T$ = operating temperature (kelvin), $M_{\mathrm{A}}=$ molecular weight $(\mathrm{g} / \mathrm{mol})$ of $\mathrm{NH}_{3}$, and $V_{\mathrm{C}}=$ chamber volume $(\mathrm{mL})$.

\section{ASSOCIATED CONTENT}

\section{Supporting Information}

The Supporting Information is available free of charge at https://pubs.acs.org/doi/10.1021/acsomega.0c03981.

Details related to the contact angle measurement of ZIF67 ; response of the sensor at individual ammonia concentrations; selectivity; reproducibility; and stability of the sensor and comparison between recently reported rGO and MOF-based ammonia sensors (PDF) 


\section{AUTHOR INFORMATION}

\section{Corresponding Authors}

Akash Deep - CSIR-Central Scientific Instruments Organisation, Chandigarh 160030, India; Academy of Scientific and Innovative Research (AcSIR), Ghaziabad 201002, India; Email: dr.akashdeep@csio.res.in

Amit L. Sharma - CSIR-Central Scientific Instruments Organisation, Chandigarh 160030, India; Academy of Scientific and Innovative Research (AcSIR), Ghaziabad 201002, India; ○ orcid.org/0000-0003-2328-5814;

Email: amitsharma csio@csio.res.in

\section{Authors}

Naini Garg - CSIR-Central Scientific Instruments Organisation, Chandigarh 160030, India; Academy of Scientific and Innovative Research (AcSIR), Ghaziabad 201002, India

Mukesh Kumar - CSIR-Central Scientific Instruments Organisation, Chandigarh 160030, India

Neelam Kumari - CSIR-Central Scientific Instruments Organisation, Chandigarh 160030, India

Complete contact information is available at: https://pubs.acs.org/10.1021/acsomega.0c03981

\section{Author Contributions}

N.G. designed the experiments, synthesized, characterized all the materials, and prepared the manuscript; M.K. and N.K. contributed in the spectroscopic and morphological data analysis; A.L.S. and A.D. supervised the work, contributed in design of experiments, interpreted the results, and edited the manuscript.

\section{Notes}

The authors declare no competing financial interest.

\section{ACKNOWLEDGMENTS}

Authors are grateful to the Director, CSIR-CSIO, Chandigarh, India, for his constant support and encouragement during this work. N.G. is grateful to Department of Science and Technology (DST), Government of India, for providing her INSPIRE fellowship (IF 170371). A.D. also acknowledges the financial support from SERB-DST (GAP-397, EMR/2016/ 006480).

\section{REFERENCES}

(1) Kanan, S.; El-kadri, O.; Abu-yousef, I.; Kanan, M. Semiconducting Metal Oxide Based Sensors for Selective Gas Pollutant Detection. Sensors 2009, 9, 8158-8196.

(2) Toxic FAQ Sheet of Ammonia; Agency for Toxic Substances and Disease Registry (ATSDR), 2004; CAS 7664-41-7.

(3) National Research Council. Acute Exposure Guideline Levels for Selected Airborne Chemicals; National Academies Press: Washington, DC, 2003; Vol. 3.

(4) Timmer, B.; Olthuis, W.; van den Berg, A. Ammonia sensors and their applications-A Review. Sens. Actuators, B 2005, 107, 666-677.

(5) Tai, H.; Duan, Z.; He, Z.; Li, X.; Xu, J.; Liu, B.; Jiang, Y. Enhanced ammonia response of $\mathrm{Ti}_{3} \mathrm{C}_{2} \mathrm{~T}_{\mathrm{x}}$ nanosheets supported by $\mathrm{TiO}_{2}$ nanoparticles at room temperature. Sens. Actuators, B 2019, 298, 126874.

(6) Tai, H.; Duan, Z.; Wang, Y.; Wang, S.; Jiang, Y. Paper-Based Sensors for Gas, Humidity, and Strain Detections: A Review. ACS Appl. Mater. Interfaces 2020, 12, 31037-31053.

(7) Zhang, Y.; Zhang, J.; Jiang, Y.; Duan, Z.; Liu, B.; Zhao, Q.; Wang, S.; Yuan, Z.; Tai, H. Ultrasensitive flexible $\mathrm{NH}_{3}$ gas sensor based on polyaniline $/ \mathrm{SrGe}_{4} \mathrm{O}_{9}$ nanocomposite with ppt-level detection ability at room temperature. Sens. Actuators, B 2020, 319, 128293.

(8) Panes-Ruiz, L. A.; Shaygan, M.; Fu, Y.; Liu, Y.; Khavrus, V.; Oswald, S.; Gemming, T.; Baraban, L.; Bezugly, V.; Cuniberti, G. Toward highly sensitive and energy efficient ammonia gas detection with modified single-walled carbon nanotubes at room temperature. ACS Sens. 2018, 3, 79-86.

(9) Mackin, C.; Schroeder, V.; Zurutuza, A.; Su, C.; Kong, J.; Swager, T. M.; Palacios, T. Chemiresistive graphene sensors for ammonia detection. ACS Appl. Mater. Interfaces 2018, 10, 1616916176.

(10) Tai, H.; Wang, S.; Duan, Z.; Jiang, Y. Evolution of breath analysis based on humidity and gas sensors: Potential and challenges. Sens. Actuators, B 2020, 318, 128104.

(11) Travlou, N. A.; Singh, K.; Rodríguez-Castellón, E.; Bandosz, T. J. $\mathrm{Cu}-\mathrm{BTC} \mathrm{MOF}-$ graphene-based hybrid materials as low concentration ammonia sensors. J. Mater. Chem. A 2015, 3, 1141711429.

(12) Talwar, V.; Singh, O.; Singh, R. C. ZnO assisted polyaniline nanofibers and its application as ammonia gas sensor. Sens. Actuators, B 2014, 191, 276-282.

(13) Miller, D. R.; Akbar, S. A.; Morris, P. A. Nanoscale metal oxidebased heterojunctions for gas sensing: A Review. Sens. Actuators, B 2014, 204, 250-272.

(14) Dey, A. Semiconductor metal oxide gas sensors: A review. Mater. Sci. Eng., B 2018, 229, 206-217.

(15) Sharma, S.; Hussain, S.; Singh, S.; Islam, S. S. MWCNTconducting polymer composite based ammonia gas sensors: A new approach for complete recovery process. Sens. Actuators, B 2014, 194, 213-219.

(16) Bai, H.; Shi, G. Gas sensors based on conducting polymers. Sensors 2007, 7, 267-307.

(17) Choi, J.; Hormes, J.; Kahol, P. K. Study of ammonia-gasinduced irreversibility in polypyrrole films. Appl. Phys. Lett. 2003, 83, $2288-2290$

(18) Campbell, M. G.; Dincă, M. Metal-organic frameworks as active materials in electronic sensor devices. Sensors 2017, 17, 1108.

(19) Kumar, P.; Deep, A.; Kim, K.-H. Metal organic frameworks for sensing applications. Trends Anal. Chem. 2015, 73, 39-53.

(20) Maduraiveeran, G.; Jin, W. Nanomaterials based electrochemical sensor and biosensor platforms for environmental applications. Trends Environ. Anal. Chem. 2017, 13, 10-23.

(21) Si, X.; Jiao, C.; Li, F.; Zhang, J.; Wang, S.; Liu, S.; Li, Z.; Sun, L.; Xu, F.; Gabelica, Z.; Schick, C. High and selective $\mathrm{CO}_{2}$ uptake, $\mathrm{H}_{2}$ storage and methanol sensing on the amine-decorated 12-connected MOF CAU-1. Energy Environ. Sci. 2011, 4, 4522-4527.

(22) Li, B.; Wen, H.-M.; Zhou, W.; Chen, B. Porous Metal-Organic Frameworks for Gas Storage and Separation: What, How, and Why? J. Phys. Chem. Lett. 2014, 5, 3468-3479.

(23) Zhang, Z.; Yao, Z.-Z.; Xiang, S.; Chen, B. Perspective of microporous metal-organic frameworks for $\mathrm{CO}_{2}$ capture and separation. Energy Environ. Sci. 2014, 7, 2868-2899.

(24) Pirzadeh, K.; Ghoreyshi, A. A.; Rahimnejad, M.; Mohammadi, $\mathrm{M}$. Electrochemical synthesis, characterization and application of a microstructure $\mathrm{Cu}_{3}(\mathrm{BTC})_{2}$ metal organic framework for $\mathrm{CO}_{2}$ and $\mathrm{CH}_{4}$ separation. Korean J. Chem. Eng. 2018, 35, 974-983.

(25) Yang, Q.; Xu, Q.; Jiang, H.-L. Metal-organic frameworks meet metal nanoparticles: synergistic effect for enhanced catalysis. Chem. Soc. Rev. 2017, 46, 4774-4808.

(26) Wang, L.; Zheng, M.; Xie, Z. Nanoscale metal-organic frameworks for drug delivery: a conventional platform with new promise. J. Mater. Chem. B 2018, 6, 707-717.

(27) Kent, C. A.; Liu, D.; Ma, L.; Papanikolas, J. M.; Meyer, T. J.; Lin, W. Light harvesting in microscale metal-organic frameworks by energy migration and interfacial electron transfer quenching. J. Am. Chem. Soc. 2011, 133, 12940-12943.

(28) Lustig, W. P.; Mukherjee, S.; Rudd, N. D.; Desai, A. V.; Li, J.; Ghosh, S. K. Metal-organic frameworks: functional luminescent and 
photonic materials for sensing applications. Chem. Soc. Rev. 2017, 46, $3242-3285$.

(29) Rui, K.; Wang, X.; Du, M.; Zhang, Y.; Wang, Q.; Ma, Z.; Zhang, Q.; Li, D.; Huang, X.; Sun, G.; Zhu, J.; Huang, W. Dual-function metal-organic framework-based wearable fibers for gas probing and energy storage. ACS Appl. Mater. Interfaces 2018, 10, 2837-2842.

(30) Zhang, W.; Tan, Y.; Gao, Y.; Wu, J.; Hu, J.; Stein, A.; Tang, B. Nanocomposites of zeolitic imidazolate frameworks on graphene oxide for pseudocapacitor applications. J. Appl. Electrochem. 2016, 46, 441-450.

(31) Wang, L.; Feng, X.; Ren, L.; Piao, Q.; Zhong, J.; Wang, Y.; Li, H.; Chen, Y.; Wang, B. Flexible solid-state supercapacitor based on a metal-organic framework interwoven by electrochemically-deposited PANI. J. Am. Chem. Soc. 2015, 137, 4920-4923.

(32) Sundriyal, S.; Shrivastav, V.; Kaur, H.; Mishra, S.; Deep, A. High-performance symmetrical supercapacitor with a combination of a ZIF-67/rGO composite electrode and a redox additive electrolyte. ACS Omega 2018, 3, 17348-17358.

(33) Hosseinian, A.; Amjad, A.; Hosseinzadeh-Khanmiri, R.; Ghorbani-Kalhor, E.; Babazadeh, M.; Vessally, E. Nanocomposite of ZIF-67 metal-organic framework with reduced graphene oxide nanosheets for high-performance supercapacitor applications. J. Mater. Sci.: Mater. Electron. 2017, 28, 18040-18048.

(34) Wang, L.; Yang, H.; Pan, G.; Miao, L.; Chen, S.; Song, Y. Polyaniline-carbon nanotubes@ zeolite imidazolate framework67carbon cloth hierarchical nanostructures for supercapacitor electrode. Electrochim. Acta 2017, 240, 16-23.

(35) Park, K. S.; Ni, Z.; Côté, A. P.; Choi, J. Y.; Huang, R.; UribeRomo, F. J.; Chae, H. K.; O’Keeffe, M.; Yaghi, O. M. Exceptional chemical and thermal stability of zeolitic imidazolate frameworks. Proc. Natl. Acad. Sci. U.S.A. 2006, 103, 10186-10191.

(36) Matatagui, D.; Sainz-Vidal, A.; Gràcia, I.; Figueras, E.; Cané, C.; Saniger, J. M. Chemoresistive gas sensor based on ZIF-8/ZIF-67 nanocrystals. Sens. Actuators, B 2018, 274, 601-608.

(37) Cui, F.; Chen, W.; Jin, L.; Zhang, H.; Jiang, Z.; Song, Z. Fabrication of ZIF-8 encapsulated $\mathrm{ZnO}$ microrods with enhanced sensing properties for $\mathrm{H}_{2}$ detection. J. Mater. Sci.: Mater. Electron. 2018, 29, 19697-19709.

(38) Jafari, N.; Zeinali, S.; Shadmehr, J. Room temperature resistive gas sensor based on ZIF-8/MWCNT/AgNPs nanocomposite for VOCs detection. J. Mater. Sci.: Mater. Electron. 2019, 30, 1233912350 .

(39) Tian, H.; Fan, H.; Li, M.; Ma, L. Zeolitic imidazolate framework coated $\mathrm{ZnO}$ nanorods as molecular sieving to improve selectivity of formaldehyde gas sensor. ACS Sens. 2016, 1, 243-250.

(40) Chen, E.-X.; Yang, H.; Zhang, J. Zeolitic imidazolate framework as formaldehyde gas sensor. Inorg. Chem. 2014, 53, 5411-5413.

(41) DMello, M. E.; Sundaram, N. G.; Kalidindi, S. B. Assembly of ZIF-67 Metal-Organic Framework over Tin Oxide Nanoparticles for Synergistic Chemiresistive $\mathrm{CO}_{2}$ Gas Sensing. Chem._Eur. J. 2018, 24, 9220-9223.

(42) Ren, G.; Li, Z.; Yang, W.; Faheem, M.; Xing, J.; Zou, X.; Pan, Q.; Zhu, G.; Du, Y. ZnO@ ZIF-8 core-shell microspheres for improved ethanol gas sensing. Sens. Actuators, B 2019, 284, 421-427.

(43) Allendorf, M. D.; Schwartzberg, A.; Stavila, V.; Talin, A. A. A roadmap to implementing metal-organic frameworks in electronic devices: challenges and critical directions. Chem.-Eur. J. 2011, 17, 11372-11388.

(44) Achmann, S.; Hagen, G.; Kita, J.; Malkowsky, I.; Kiener, C.; Moos, R. Metal-organic frameworks for sensing applications in the gas phase. Sensors 2009, 9, 1574-1589.

(45) Taniselass, S.; Arshad, M. K. M.; Gopinath, S. C. B. Graphenebased electrochemical biosensors for monitoring noncommunicable disease biomarkers. Biosens. Bioelectron. 2019, 130, 276-292.

(46) Sajid, M.; Baig, N.; Alhooshani, K. Chemically modified electrodes for electrochemical detection of dopamine: Challenges and opportunities. TrAC, Trends Anal. Chem. 2019, 118, 368-385.
(47) Zhu, Y.; Murali, S.; Cai, W.; Li, X.; Suk, J. W.; Potts, J. R.; Ruoff, R. S. Graphene and graphene oxide: synthesis, properties, and applications. Adv. Mater. 2010, 22, 3906-3924.

(48) Jawaid, M.; Ahmad, A.; Lokhat, D. Graphene-Based Nanotechnologies for Energy and Environmental Applications; Micro and Nano Technologies Series; Elsevier, 2019.

(49) Krishnan, S. K.; Singh, E.; Singh, P.; Meyyappan, M.; Nalwa, H. $S$. A review on graphene-based nanocomposites for electrochemical and fluorescent biosensors. RSC Adv. 2019, 9, 8778-8881.

(50) Yuan, W.; Shi, G. Graphene-based gas sensors. J. Mater. Chem. A 2013, 1, 10078-10091.

(51) Feng, Q.; Li, X.; Wang, J. Percolation effect of reduced graphene oxide (rGO) on ammonia sensing of rGO-SnO2 composite based sensor. Sens. Actuators, B 2017, 243, 1115-1126.

(52) Huang, X.; Hu, N.; Gao, R.; Yu, Y.; Wang, Y.; Yang, Z.; Kong, E. S.-W.; Wei, H.; Zhang, Y. Reduced graphene oxide-polyaniline hybrid: preparation, characterization and its applications for ammonia gas sensing. J. Mater. Chem. 2012, 22, 22488-22495.

(53) Hu, N.; Yang, Z.; Wang, Y.; Zhang, L.; Wang, Y.; Huang, X.; Wei, H.; Wei, L.; Zhang, Y. Ultrafast and sensitive room temperature $\mathrm{NH}_{3}$ gas sensors based on chemically reduced graphene oxide. Nanotechnology 2013, 25, 025502.

(54) Hu, N.; Wang, Y.; Chai, J.; Gao, R.; Yang, Z.; Kong, E. S.-W.; Zhang, Y. Gas sensor based on p-phenylenediamine reduced graphene oxide. Sens. Actuators, B 2012, 163, 107-114.

(55) Lee, C.-T.; Wang, Y.-S. High-performance room temperature $\mathrm{NH} 3$ gas sensors based on polyaniline-reduced graphene oxide nanocomposite sensitive membrane. J. Alloys Compd. 2019, 789, 693696.

(56) Qin, Y.; Zhang, B.; Zhang, Z. Combination of PPy with threedimensional rGO to construct bioinspired nanocomposite for $\mathrm{NH}_{3}$ sensing enhancement. Org. Electron. 2019, 70, 240-245.

(57) Qian, J.; Sun, F.; Qin, L. Hydrothermal synthesis of zeolitic imidazolate framework-67 (ZIF-67) nanocrystals. Mater. Lett. 2012, 82, 220-223.

(58) Dong, Y.; Duan, C.; Sheng, Q.; Zheng, J. Preparation of Ag@ zeolitic imidazolate framework-67 at room temperature for electrochemical sensing of hydrogen peroxide. Analyst 2019, 144, 521-529.

(59) Cheng, N.; Wang, H.; Li, X.; Zhu, L. Amperometric glucose biosensor based on integration of glucose oxidase with palladium nanoparticles/reduced graphene oxide nanocomposite. Am. J. Anal. Chem. 2012, 3, 312-319.

(60) Jamil, N.; Othman, N. H.; Alias, N. H.; Shahruddin, M. Z.; Roslan, R. A.; Lau, W. J.; Ismail, A. F. Mixed matrix membranes incorporated with reduced graphene oxide (rGO) and zeolitic imidazole framework-8 (ZIF-8) nanofillers for gas separation. J. Solid State Chem. 2019, 270, 419-427.

(61) Asgharnejad, L.; Abbasi, A.; Shakeri, A. Ni-based metal-organic framework/GO nanocomposites as selective adsorbent for $\mathrm{CO}_{2}$ over $\mathrm{N}_{2}$. Microporous Mesoporous Mater. 2018, 262, 227-234.

(62) Petit, C.; Bandosz, T. J. Enhanced adsorption of ammonia on metal-organic framework/graphite oxide composites: analysis of surface interactions. Adv. Funct. Mater. 2010, 20, 111-118.

(63) Panchariya, D. K.; Rai, R. K.; Anil Kumar, E.; Singh, S. K. Core-shell zeolitic imidazolate frameworks for enhanced hydrogen storage. ACS Omega 2018, 3, 167-175.

(64) Khan, A.; Ali, M.; Ilyas, A.; Naik, P.; Vankelecom, I. F. J.; Gilani, M. A.; Bilad, M. R.; Sajjad, Z.; Khan, A. L. ZIF-67 filled PDMS mixed matrix membranes for recovery of ethanol via pervaporation. Sep. Purif. Technol. 2018, 206, 50-58.

(65) Qin, J.; Wang, S.; Wang, X. Visible-light reduction $\mathrm{CO}_{2}$ with dodecahedral zeolitic imidazolate framework ZIF-67 as an efficient cocatalyst. Appl. Catal., B 2017, 209, 476-482.

(66) Zhou, K.; Mousavi, B.; Luo, Z.; Phatanasri, S.; Chaemchuen, S.; Verpoort, F. Characterization and properties of $\mathrm{Zn} / \mathrm{Co}$ zeolitic imidazolate frameworks vs. ZIF-8 and ZIF-67. J. Mater. Chem. A 2017, 5, 952-957. 
(67) Jayaramulu, K.; Geyer, F.; Schneemann, A.; Kment, Š.; Otyepka, M.; Zboril, R.; Vollmer, D.; Fischer, R. A. Hydrophobic Metal-Organic Frameworks. Adv. Mater. 2019, 31, 1900820.

(68) Kim, D.; Kim, D. W.; Buyukcakir, O.; Kim, M.-K.; Polychronopoulou, K.; Coskun, A. Highly hydrophobic ZIF-8/carbon nitride foam with hierarchical porosity for oil capture and chemical fixation of $\mathrm{CO}_{2}$. Adv. Funct. Mater. 2017, 27, 1700706.

(69) Duan, Z.; Jiang, Y.; Yan, M.; Wang, S.; Yuan, Z.; Zhao, Q.; Sun, P.; Xie, G.; Du, X.; Tai, H. Facile, flexible, cost-saving, and environment-friendly paper-based humidity sensor for multifunctional applications. ACS Appl. Mater. Interfaces 2019, 11, 21840-21849.

(70) Banica, F. G. Chemical Sensors and Biosensors: Fundamentals and Applications; John Wiley \& Sons, 2012; pp 1-20.

(71) Assen, A. H.; Yassine, O.; Shekhah, O.; Eddaoudi, M.; Salama, K. N. MOFs for the sensitive detection of ammonia: deployment of fcu-MOF thin films as effective chemical capacitive sensors. ACS Sens. 2017, 2, 1294-1301.

(72) Zhang, J.; Lu, H.; Zhang, L.; Leng, D.; Zhang, Y.; Wang, W.; Gao, Y.; Lu, H.; Gao, J.; Zhu, G.; Yang, Z.; Wang, C. Metal-organic framework-derived $\mathrm{ZnO}$ hollow nanocages functionalized with nanoscale Ag catalysts for enhanced ethanol sensing properties. Sens. Actuators, B 2019, 291, 458-469.

(73) Ri, G.-C.; Kim, J.-S.; Yu, C.-J. Role of water molecules in enhancing the proton conductivity on reduced graphene oxide under high humidity. Phys. Rev. Appl. 2018, 10, 034018.

(74) Marcano, D. C.; Kosynkin, D. V.; Berlin, J. M.; Sinitskii, A.; Sun, Z.; Slesarev, A.; Alemany, L. B.; Lu, W.; Tour, J. M. Improved synthesis of graphene oxide. ACS Nano 2010, 4, 4806-4814.

(75) Li, Y.; Gong, J.; He, G.; Deng, Y. Enhancement of photoresponse and UV-assisted gas sensing with Au decorated $\mathrm{ZnO}$ nanofibers. Mater. Chem. Phys. 2012, 134, 1172-1178. 